\title{
Linking lead pollution in ice cores to ancient history
}

\section{Nathan Chellman and Joe McConnell}

\section{Human impacts on Earth}

Both modern and ancient human societies have left a significant imprint on the environment over the past few thousand years. From the ancient Romans, who constructed buildings 2000 years ago that still stand today such as the Colosseum and Pantheon, to the present day where cities, roads, and towns are spread out all over the globe, we have had an undeniable impact on our planet. But did you know that humans have had such a far-reaching impact on the environment that scientists can track the progress of human society - starting from ancient civilizations such as the Romans through the Middle Ages and to the present day - by measuring pollution in snow and ice from places as far away as Greenland?

Lead - a toxic heavy metal harmful to human health - is one of the pollutants emitted by human activities. Until 50 years ago, when the harmful effects of lead were recognized and emissions were significantly lowered by government regulations, the amount of lead pollution was closely related to the economic and industrial development of societies. As civilizations mined and extracted more metals or burned fossil fuels, lead emissions increased. When there were wars or pandemics that caused industrial activity to stall, however, lead emissions decreased dramatically. By measuring the amount of lead frozen in Greenland ice cores, scientists can create year-by-year records of lead pollution to learn about the industrial progress of societies in Europe and North America. In this article, we will explore how lead pollution has changed during the past 2000 years, and what can we learn from lead measured in remote ice cores from Greenland.
Figure 1: This map shows how far away Greenland (blue) in sources in North America and from main lead en ice cores used in this Europe. The black crosses indicate the ice compire was a major lead project. Did you know that Keep reading to find out why.

\section{Evidence in the ice}

The chemicals, such as lead, that are found in the ice in Greenland, Antarctica, and high-mountain glaciers provide information about Earth's climate and atmosphere, allowing scientists to understand how the environment has changed over thousands of years. Human industrial activities - such as coal burning in factories or powerplants, gasoline burning from cars, or mining to make metals - emit pollutants into the atmosphere. Lead is one of these pollutants, and it can be emitted as particles that are 100 times smaller than the diameter of a human hair - so small that they can stay in the air for weeks and travel great distances through the atmosphere. Each year, winds carry these lead particles, emitted by factories, mines, or car exhausts, thousands of kilometers across Europe and North America to Greenland where they eventually fall onto the ice sheet and are buried by a layer of snow (Fig. 1).

As layers of snow continue to fall year after year, the snow from the previous years is buried and eventually transformed into ice, locking the tiny lead particles within the ice sheet and preserving a record of pollution that can extend thousands of years into the past. To get ice samples that are thousands of years old, scientists use a special ice-core drill to bore through the ice, meter by meter, and extract ice samples captured inside the drill (Fig. 2). An ice core is comprised of hundreds or thousands of individual samples of ice that represent a vertical profile through the glacier when they are stacked on top of each other. Because glacial ice is so clean - meaning naturally there are very low concentrations of chemicals in the ice - ice cores have been particularly useful for scientists to study pollution since even very small amounts of certain chemicals can be detected in ice.
Figure 2: Cutting end of the ice-core drill. The three blades cut around the ice core, which you can see just inside the hollow section of the drill. 


\section{How is lead measured?}

Measuring lead in an ice core requires specialized techniques as well as sensitive scientific analysis equipment and machines, which scientists call "instruments". Since there are small amounts of lead almost everywhere in the environment, the ice cores must be decontaminated by removing the outer layers that have been exposed to the air (Fig. 3). Then, the ice is melted and this water is sent to instruments that can make measurements of lead concentrations as low as 70 parts per quadrillion! One part per quadrillion is so small it is hard to visualize. You can try thinking of one part per billion first - this is like looking for one milliliter of water in an entire swimming pool, and one part per quadrillion is a million times smaller than that! The instruments that scientists use to detect lead are measuring tiny amounts of pollution in the ice.

\section{Lead pollution from the Romans to present day}

Figure 4 shows lead data compiled from 12 different ice cores from Greenland. The records go back to 800 years Before the Common Era (BCE), or about 2800 years before present day. The data show that between 2800 years ago and 1970 (just 50 years ago as we write this), lead pollution increased by over 300 -fold! Even as far back as 2000 years ago during the ancient Roman Empire, we are able to detect lead pollution in the Greenland ice cores. What could have caused lead pollution so long ago? In order to make coins, the Romans melted lead/silver ores from mines to extract silver. As they heated up the ore to extract the silver, lead escaped as a waste product and entered the atmosphere to be eventually transported to Greenland. This process of heating up ores to extract metals is called smelting, and is also what caused lead pollution to increase during the Middle Ages.

Starting around 200 years ago at the start of the Industrial Revolution, humans discovered that they could burn fossil fuels - coal and oil - to generate enormous amounts of energy. Similar to smelting, when coal is burned without any technology to control emissions, lead is emitted as a waste product since fossil fuels naturally contain lead. In addition, lead previously was added to gasoline to help car engines run better. The combination of coal, oil, and gasoline burning over the past 200 years led to massive increases in lead pollution measured in Greenland that peaked in about 1970. Once people realized that lead was a toxic metal that could harm humans and that lead pollution was a serious problem, governments enacted legislation to clean up the environment by reducing lead emissions. As a result of such laws, between 1970 and today lead pollution has decreased 80\% a major improvement. However, there is still room to improve because lead concentrations in the Arctic today are still at least 60 times higher than they were before humans began to affect the environment.

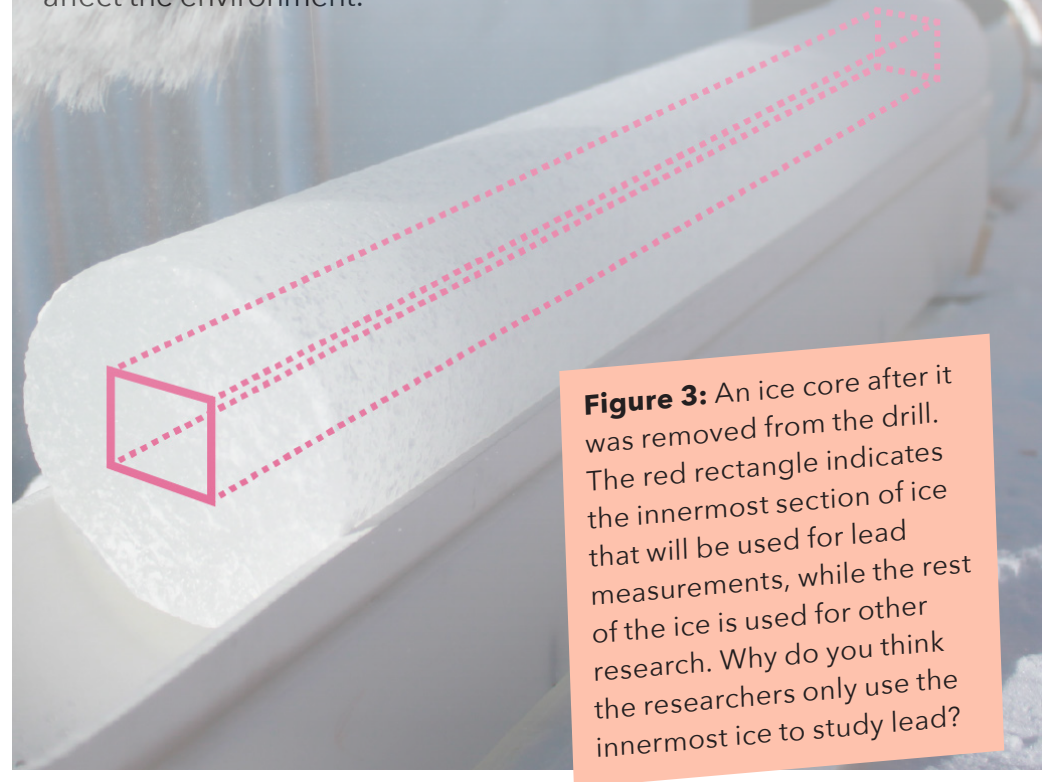

\section{The Anthropocene?}

Scientists use what is called the "geologic time scale" to refer to different periods in Earth's history. For example, dinosaurs roamed the earth millions of years ago during the Triassic, Jurassic, and Cretaceous periods. The most recent ice age that ended about 12,000 years ago - when much of North America and Europe were covered in thick ice sheets - was called the Pleistocene. Some researchers have argued that humans have modified Earth in such a profound way that we now live in a new geologic era: the Anthropocene. Based on this study and what you see around you, do you think that humans have altered the planet significantly enough to justify naming a new geologic time period? (3)

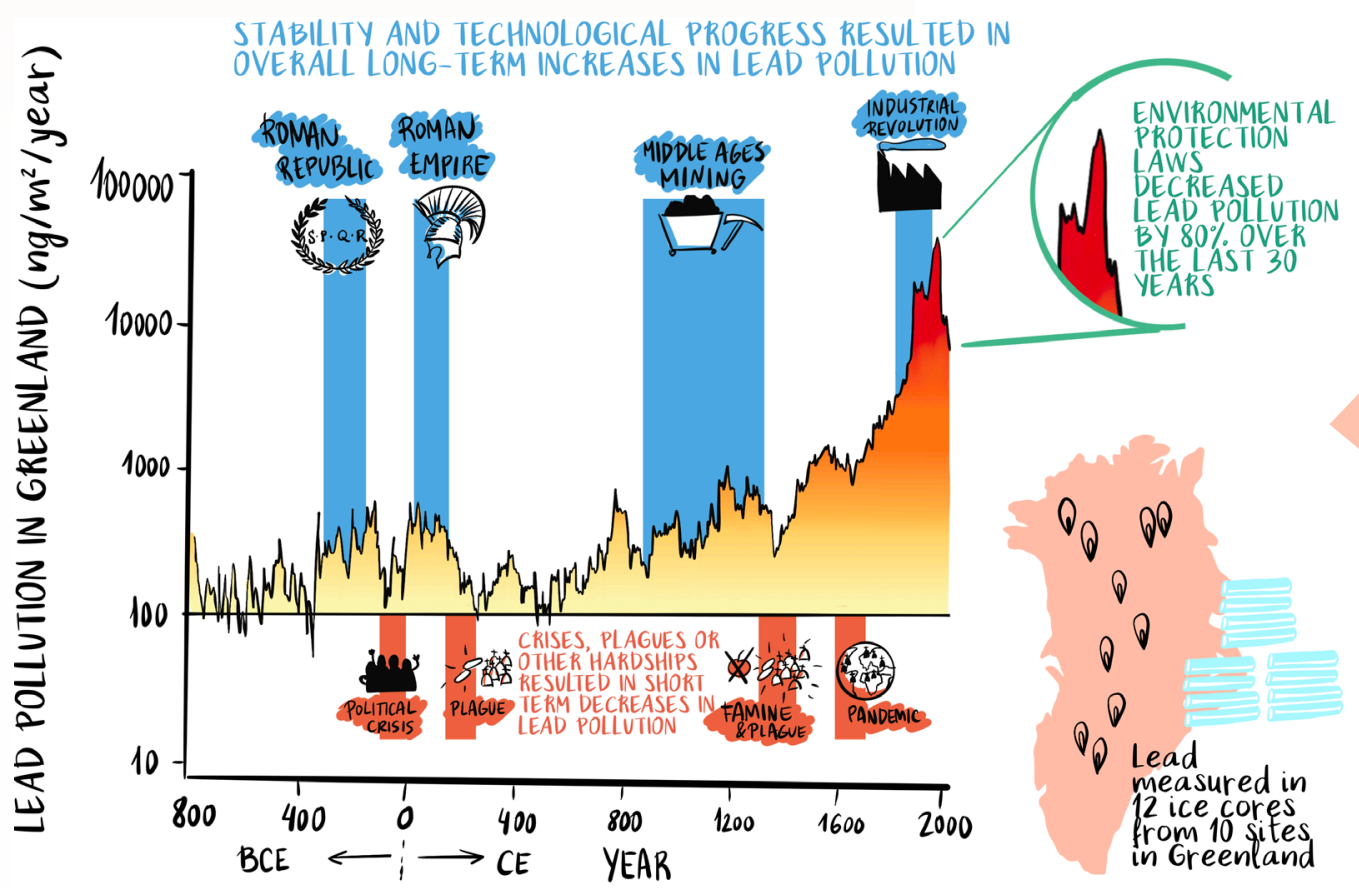

Figure 4: Average lead pollution measured in 12 Greenland ice cores. Note that the vertical axis is a that the vertic (not linear!) scale. Why do you think the researchers used many ice researchers us just one for cores inste Why do you think lead pollution decreased during plagues or famines but increased when there was political stability, more mining, or technological improvements? 